
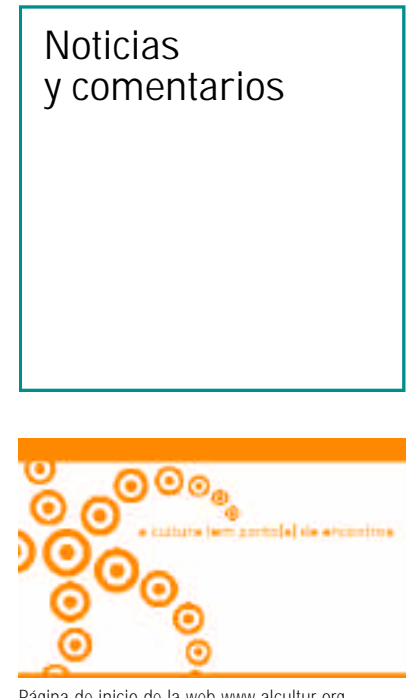

Página de inicio de la web www.alcultur.org

\title{
Cultura, educación y ciudadanía determinan las líneas estratégicas de los Encuentros Alcultur
}

"Os decretos podem outorgar cidadania, mas ser-se cidadão não dispensa um activo empenhamento próprio"

Este fragmento del texto de la conferencia "Cultura, Educación y Ciudadano" impartida por el profesor José Barata Moura, rector de la Universidad de Lisboa, expresa y sintetiza de forma marcada y firme lo que significan los "Encuentros AlCultur" y lo que fueron sus dos primeras ediciones en las ciudades de Portalegre, en el año 2004, y de Faro, en el 2005 (22 al 26 de noviembre).

La ciudadanía integra y determina, así, la identidad de este evento. Para nosotros promover, organizar y participar en los "Encuentros AlCultur" es también un acto de ciudadanía y una forma de construir cultura:

$>$ La cultura es condición esencial del ejercicio de la ciudadanía y es, o debería ser, una de las dimensiones estructurantes de los procesos sociales.

> La cultura se concibe no como la sacralización del pasado y del conocimiento sino como un sistema complejo de actividades y prácticas, de actitudes y comportamientos, de valores, de potencialidades de experimentación, innovación y creatividad, y de capacidades para responder a los desafíos de la realidad en evolución permanente. $>$ Es la cultura la que asegura los puentes entre la tradición y la experimentación, entre lo que ya es patrimonio y la contemporaneidad que ha de serlo, entre el pasado y el futuro (re)construidos en el presente. $>$ Asumimos la defensa de las identidades culturales de los territorios / comunidades locales entendidas como dimensión de progreso, evolución, desarrollo y cooperación (integrando nuevos factores de identidad emergentes de contemporaneidad) y no en una perspectiva reaccionaria de estancamiento, proteccionismo, autosuficiencia y aislamiento.

$>$ Consideramos que la cultura o tal vez, en un contexto de globalización, las culturas deben ser entendidas simultáneamente como garantía de las múltiples identidades individuales y colectivas o como la expresión plural de la diversidad y de la libertad.

$>$ Es la libertad cultural la que da cuerpo y forma a la ciudadanía y es expresión (y condición) de la independencia, de la autonomía y de la diversidad de los pueblos y de los ciudadanos.

$>$ Entendemos la cultura y la ciudadanía como hechos determinantes del desarrollo integrado de los individuos y de las comunidades y, en ese sentido, como pilares de las políticas públicas (fundamentales) al senvicio de los ciudadanos: políticas públicas que integren y promuevan la información y el conocimiento como elementos centrales de la cultura y de la ciudadanía y como instrumentos esenciales del desarrollo; políticas públicas que articulen el servicio público con la iniciativa de los ciudadanos, individualmente considerados o agrupados en asociaciones, instituciones y entidades culturales, empresas y otras organizaciones; políticas públicas que garanticen (directamente 0 apoyando a los agentes culturales locales) redes de infraestructuras y equipamientos culturales de calidad y que aseguren y articulen las dimensiones global, nacional, regional y local, contribuyendo para la sostenibilidad del desarrollo local.

Los "Encuentros AlCultur" asumen igualmente el desarrollo local y la descentralización cultural como componentes de identidad fundamentales, conscientes de que, "descentralizar es crear y fijar nuevas centralidades". Desde esta perspectiva:

$>$ Reconocemos especial importancia y queremos contribuir para estimular a las comunidades locales para reafirmar sus identidades culturales y ponerlas en valor, querer su patrimonio, querer a sus artistas y creadores.

$>$ Consideramos determinante favorecer la autoestima de los ciudadanos en la relación con su comunidad y territorio y promover la reafirmación de las comunidades locales y regionales a través de la cultura.

$>$ Entendemos la descentralización de la oferta cultural también como un proceso de estructuración y rehabilitación del territorio, lo que puede verse favorecido, por ejemplo, a través de la deslocalización territorial de agentes culturales con calidad y sostenibilidad reconocidas, a través de apoyos al asociacionismo popular entendido como instrumento privilegiado para promover el desarrollo y participación de los ciudadanos, y a través de la implementación y/ o consolidación de redes de programación cultural y programas de difusión que faciliten y democraticen el acceso a los bienes culturales, que integran creadores, autores y productores locales, y que sustenten la itinerancia interlocal.

Consideramos que la cultura y la educación -indisociables de las dimensiones política, económica y social del desarrollo y de la democracia, que son condiciones materiales de su realización- constituyen factores fundamentales y determinantes de reafirmación de nuestras identidades sociales e individuales, esto es, lo que, en cada momento, da sentido a nuestra vidas y a nuestra relación con los otros y con el mundo. Por eso, la cultura y la educación son problemática siempre presente en los "Encuentros AlCultur":

> Defendemos políticas culturales públicas prioritariamente orientadas para la articulación con la educación y con el sistema educativo porque consideramos que la escuela es referente esencial 

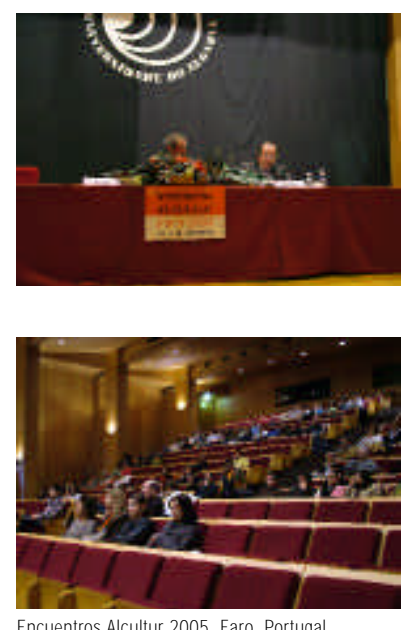

Encuentros Alcultur 2005. Faro, Portugal para los territorios / comunidades locales y, consecuentemente, son espacios privilegiados de (y para la) intervención cultural.

$>$ Asumimos la defensa de la convergencia de las políticas educativas y de las políticas culturales como elemento esencial para el desarrollo de las comunidades y estructurante de la formación de los ciudadanos, en un contexto en el que la información y el conocimiento se soportan en valores y principios, y dan expresión a la libertad y diversidad cultural.

Defendemos la coexistencia y la relación creativa, y creadora, entre tradición y contemporaneidad, entre patrimonio y experimentación, entre lo que es llamado popular y lo calificado como erudito, y por eso consideramos que todas las expresiones artísticas y culturales, y sus protagonistas deben tener y tienen su lugar en estos "Encuentros".

Los "Encuentros AlCultur" se consideran punto de encuentro(s) de diferentes personas y entidades de la (y de) cultura. Pretenden ser una plataforma potenciadora de aprendizajes, de conocimiento, de innovación y creatividad, de nuevas ideas y proyectos y de implementación de nuevas redes de cooperación, y constituyen un recurso para el desarrollo local de las ciudades y regiones donde se realizan.
Los "Encuentros AlCultur" se materializan "provocando" encuentros, y también desencuentros, en un cuadro de emergencia de las especificidades, de las diversidades y de las diferencias que caracterizan a los múltiples actores que, asumiendo la ciudadanía, intervienen en la cultura y en la educación contribuyendo al desarrollo de las personas y las comunidades.

Asumimos, finalmente, como objetivo estratégico la extensión de la intervención de los "Encuentros AlCultur" al "espacio cultural" de la Península Ibérica y de los mundos hispánico y luso, porque acreditamos que en este Mundo cada vez más globalizado, nuestras culturas, nuestros idiomas y nuestras identidades (y diversidades) culturales, constituyen un patrimonio común que tenemos el deber y la responsabilidad de preservar y salvaguardar, pues son portadoras del designio de la libertad cultural en cuanto condición del desarrollo de los pueblos y de los ciudadanos.

Vítor Martelo

Coordinador de la Comisión Organizadora

de los Encuentros AlCultur

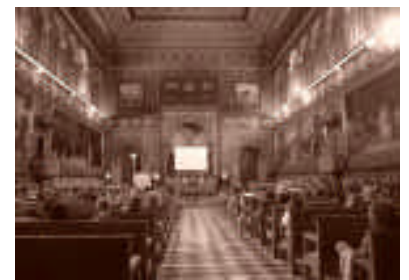

Imagen de la celebración del congreso

\section{El Grupo Español del IIC reclama cambios en las políticas de investigación en conservación y restauración}

El II Congreso del Grupo Español del IIC, bajo el lema "Investigación en Conservación y Restauración", celebrado en la Universidad de Barcelona del 9 al 11 de noviembre de 2005, contó con la presencia de cerca de cuatrocientos asistentes relaciona dos con este ámbito profesional y procedentes tanto de nuestro país como de Iberoamérica y Europa.

Durante tres días consecutivos estudiantes, investigadores y técnicos vinculados a organismos oficiales y empresas privadas escucharon los trabajos presentados sobre criterios y planteamientos metodológicos, el empleo de las nuevas tecnologías en los estudios y técnicas de intervención, y la investigación de las fuentes documentales, aplicados a áreas tan dispares como el papel, los textiles, la pintura, los monumentos, el arte contemporáneo, la arqueología, la fotografía, etc.

Al finalizar cada una de las jornadas se celebró una mesa redonda para debatir los diferentes temas que preocupan a los profesionales y con la intención de intentar llegar a una serie de conclusiones que pudieran ser trasladadas a los organismos responsables.

La última de las mesas versó sobre las Propuestas para una política de investigación en Conservación y
Restauración, moderada por Salvador García (restaurador, Universidad de Barcelona). Participaron como ponentes: Álvaro Martínez-Novillo (Subdirector General del Instituto del Patrimonio Histórico Español), J oaquín Barrio (arqueólogo y restaurador, Universidad Autónoma de Madrid), Nieves Valentín (Bióloga, IPHE), Bonaventura Bassegoda (Ministerio de Educación y Ciencia), Giuseppe Basile (Istituto Centrale del Restauro, Roma).

En esta mesa se suscitó una gran polémica y animado debate, llegando finalmente a consensuar una serie de cuestiones de interés general y que intentaremos transmitir a los responsables del diseño y desarrollo de estas políticas de investigación:

$>$ Se hace evidente la necesidad de elaborar planes de conservación y restauración, así como de establecer, por parte de las instituciones, un programa de proyectos prioritarios.

$>$ El Ministerio, en sus convocatorias de proyectos, ha incluido la conservación-restauración dentro del área de Historia y, actualmente, en la de Arte. Sería fundamental que estos proyectos no estuviesen adscritos a esas áreas, sino que existiese la específica de conservación-restauración. De ese modo, tanto 